\title{
Overview of Hydatid Disease in Iranian Children
}

\author{
Alireza Fahimzad ${ }^{1}$; Abdollah Karimi ${ }^{1}$; Sedigheh Rafiei Tabatabaei ${ }^{1}$; Shahnaz Armin ${ }^{1}$; \\ Roxana Mansour Ghanaei ${ }^{1}$; Fatemeh Fallah ${ }^{1}$; Farideh Shiva ${ }^{1}$; Fatholla Roshanzamir ${ }^{2}$; \\ Nasser Mostafavi ${ }^{3}$; Shirin Sayyahfar ${ }^{4}$; Iraj Sedighi ${ }^{5}$; Gholamreza Soleimani ${ }^{6}$; Manijeh \\ Kahbazi $^{7}$; Roya Nikfar $^{8}$; Masomeh Abedini ${ }^{9}$; Reza Arjmand ${ }^{10}$; Fatemeh Abdollah Gorji ${ }^{11}$; \\ Nava Safaei ${ }^{12}$; Shokofeh Noroozi ${ }^{12}$; Azadeh Gharooei ${ }^{12, *}$ \\ ${ }_{1}^{1}$ Pediatric Infections Research Center, Mofid Children's Hospital, Shahid Beheshti University of Medical Sciences, Tehran, IR Iran \\ ${ }_{3}^{2}$ Pediatric Surgery Research Center, Shahid Beheshti University of Medical Sciences, Tehran, IR Iran \\ ${ }^{3}$ Department of Pediatrics, Infectious Disease and Tropical Medicine Research Center, Isfahan University of Medical Sciences, Isfahan, IR Iran \\ ${ }_{5}^{4}$ Department of Pediatrics, Ali Asghar Children Hospital, Iran University of Medical Sciences, Tehran, IR Iran \\ 5 Department of Pediatrics, Faculty of Medicine, Hamadan University of Medical Sciences, Hamadan, IR Iran \\ ${ }^{6}$ Children and Adolescent Health Research Center, Zahedan University of Medical Sciences, Zahedan, IR Iran \\ 7 Tuberculosis and Pediatric Infectious Disease Research Center, Arak University of Medical Sciences, Arak, IR Iran \\ 8 Department of Pediatric Infectious Diseases, Ahvaz Jundishapur University of Medical Sciences, Ahvaz, IR Iran \\ ${ }_{9}^{9}$ Department of Pediatrics, Faculty of Medicine, Sanandaj University of Medical Sciences, Sanandaj, IR Iran \\ Department of Pediatrics, Faculty of Medicine, Sanandaj University of Medical Sciences, Sanandaj, IR
${ }^{10}$ Department of Pediatrics, Faculty of Medicine, Alborz University of Medical Sciences, Karaj, IR Iran \\ ${ }_{11}^{11}$ Medical Research Development Center, Shahid Beheshti University of Medical Sciences, Tehran, IR Iran \\ ${ }_{12}$ Medical Research Development Center, Shahid Beheshti University of Medical Sciences, Tehran, IR Iran \\ *Corresponding author: Azadeh Gharooei, Medical Faculty, Shahid Beheshti University of Medical Sciences, Tehran, IR Iran. Tel/Fax: +98-2122226941, E-mail: azadeh.gh67@gmail.com
}

Received: May 19, 2015; Revised: May 26, 2015; Accepted: May 30, 2015

Background: Hydatid disease (HD) is still an important health hazard in the world. This disease is a parasitic infestation endemic in many sheep- and cattle-raising areas such as Iran.

Objectives: This study aimed to review the clinical manifestations, laboratory aspects, imaging findings, and management of HD.

Patients and Methods: Data were collected from the medical records of patients diagnosed with HD in eight referral hospitals in different provinces of Iran from 2001 to 2014.

Results: Overall, 161 children at a mean age of $9.25 \pm 3.37$ years (age range $=1$ - 15 years old) hospitalized with a definite diagnosis of the hydatid cyst between 2001 and 2014 were studied. The male-to-female ratio was 1.6:1. The most commonly involved organ was the lung (67.1\%), followed by the liver (44.1\%) and a combined liver and lung involvement was found in $15.5 \%$ of the patients. The cysts were found more frequently in the right lobe of the liver and lung than in the left lobe. The most frequent complaints were fever (35.4\%)and abdominal pain (31.7\%), and the most frequent sign was an abdominal mass in the liver involvement and cough in the lung involvement. There was a high eosinophil count $(>500 / \mathrm{micL}$ ) in $41 \%$ of our cases. A high erythrocyte sedimentation rate $(>30)$ or positive C-reactive protein (based on the qualitative method) was found in $18.6 \%$ of the patients and leukocytosis $>15000 / \mathrm{micL}$ in $29.2 \%$ of the children. Ultrasonography was the main imaging test, with an accuracy rate of $96 \%$, and chest X-ray was helpful in $88.6 \%$ of the cases. Surgery was performed in $89 \%$ of the patients, and selective patients underwent percutaneous aspiration-injection-reaspiration drainage or medical treatment.

Conclusions: The lung was the most commonly involved organ in the children recruited in the present study. Given the high probability of multiple organ involvement, we recommend that patients with $\mathrm{HD}$ be assessed via ultrasonography and chest X-ray. In endemic regions, unexplained eosinophilia should be considered as a parasitic disease like HD and its complications.

Keywords: Echinococcosis; Parasitic Diseases; Children

\section{Background}

Hydatid disease (HD), also known as hydatidosis, is still a global problem in highly endemic areas such as Iran $(1,2)$. The hydatid cyst is the larval stage of Echinococcus granulosus, which is hosted by dogs and other canines $(3,4)$. Humans are intermediate hosts by eating the tapeworm eggs (5). According to recent estimations, echinococcosis is responsible for about $1-220 / 10000$ infections in the common areas $(2,6,7)$.

HD is commonly asymptomatic, and often the cysts are detected incidentally (8). In other cases, the symptoms vary largely and are non-specific, depending on the location, size, rupture, and infection of the cysts (9). The liver and lung are the most commonly involved organs in humans; and in children, the lung is more frequently infected (10-14). An elevated eosinophil count in a patient from an endemic region accompanied by non-specific symptoms such as abdominal pain, abdominal mass, and cough, is suggestive of HD (15). The diagnosis is usually made via

Copyright (C) 2015, Pediartric Infections Research Center. This is an open-access article distributed under the terms of the Creative Commons Attribution-NonCommercial 4.0 International License (http://creativecommons.org/licenses/by-nc/4.0/) which permits copy and redistribute the material just in noncommercial usages, provided the original work is properly cited. 
imaging modalities (i.e. ultrasonography and chest Xray) and confirmed by pathology (16). Surgery is the chief therapeutic method for the management of HD, although currently percutaneous aspiration-injection-reaspiration drainage is regarded as a first choice in many cases $(9,14)$.

The present study was performed to evaluate the epidemiological aspects, clinical presentations, paraclinical findings, and management of HD in Iranian children.

\section{Objectives}

We sought to review the clinical manifestations, laboratory aspects, imaging findings, and management of HD.

\section{Patients and Methods}

In this retrospective study, we investigated the medical records of 161 patients ( 1 - 15 years old) with a definite diagnosis of HD admitted to eight major referral hospitals of Iran during a 13-year period (2001 - 2013). Data were collected on sex, age, clinical manifestations, anatomical location of the cysts, size and number of the cysts, laboratory tests, and therapeutic management. Statistical analysis was carried out using statistical package for the social sciences (SPSS) version 18.

\section{Results}

The study population consisted of 99 (61.5\%) boys and 62 (38.5\%) girls (range $=1$ - 15 years old) from eight teaching referral hospitals around Iran (Table 1 ).

Echinococcosis was diagnosed in all our patients via pathology. The mean age of the study population was $9.25 \pm$ 3.37 years, and most of the affected patients (49.1\%) were in the age range of 6 to 10 years old (Figure 1 ).

The most frequent anatomical location of the hydatid cysts was the lung (in 108 (67.1\%) patients), followed by the liver (in 71 (44.1\%) patients). Additionally, the cysts were detected in the kidney (2.5\%), spleen $(2.5 \%)$, brain (1.9\%), colon (1.2\%), heart (0.6\%) and eye (0.6\%). Multiple organ involvement was found in $32(19.8 \%)$ patients, with a single-to-multiple ratio of about $4: 1$. There was no significant statistical difference between age $(\mathrm{P}=0.551)$ or gen$\operatorname{der}(P=0.243)$ and the anatomical location of the cysts.

Our patients had totally 335 cysts: 181 (54\%) with rightsided and 138 (41\%) with left-sided cysts. Regarding size, 130 (39\%) cysts were smaller than $5 \mathrm{~cm}$ in diameter, 157 (47\%) cysts were between 5 and $10 \mathrm{~cm}$ in diameter, and 47 (14\%) cysts were more than $10 \mathrm{~cm}$ in diameter (Table 2).

Fever was the most common complaint (35.4\%). Cough was the most common symptom associated with the lung hydatid cyst (29.8\%) and an abdominal mass was more common in the liver hydatidosis (9.3\%) (Table 3$)$.

Laboratory data showed eosinophilia $(\geq 500 / \mathrm{micL})$ in 66 children, leukocytosis (WBC $\geq 15000 / \mathrm{micL}$ ) in 47 patients, erythrocyte sedimentation rate (ESR) $\geq 30$ and positive Creactive protein (CRP) in 30 patients, and anemia $(\mathrm{Hb} \leq 11$ $\mathrm{g} / \mathrm{dL}$ ) in 28 patients. We assessed the abdominal sonography reports in 87 patients, which revealed the hydatid liver cyst in 83 (95.4\%) cases. There were 79 chest X-ray reports, 70 (88.6\%) of which suggested the lung hydatid cyst. Computed tomography (CT) scan confirmed the diagnosis in all the patients suspected of having the cyst (Table 4).

Table 1. Number of the Patients From the Eight Teaching Referral Hospitals ${ }^{\text {a }}$

\begin{tabular}{lc}
\hline University-Hospital & Values \\
\hline Isfahan-Emam Hosein & $45(28)$ \\
\hline Shanhid Beheshti-Mofid & $32(19.9)$ \\
Zahedan-Ali Ebne Abitaleb & $24(14.9)$ \\
\hline Kordestan-Besat & $14(8.7)$ \\
Kermanshah-Emam Reza & $13(8.1)$ \\
Iran-Ali Asghar & $12(7.5)$ \\
Hamedan-Besat & $12(7.5)$ \\
Arak-Amir Kabir & $9(5.6)$ \\
Total & $161(100)$ \\
\hline
\end{tabular}

${ }^{\mathrm{a}}$ Values are presented as No. (\%).

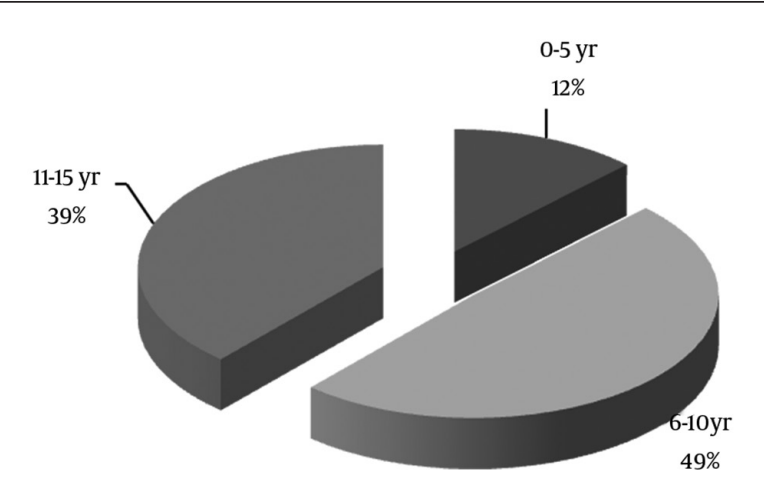

Figure 1. Distribution of the Patients' Age

Table 2. Location of the Hydatid Cysts in the 161 Patients ${ }^{a}$

\begin{tabular}{|lcc}
\hline Location & No. of Patients & No. of Cysts \\
\hline Liver & $71(44.1)$ & $137(40.5)$ \\
\hline Right lobe & $54(57.4)$ & $78(56.9)$ \\
\hline Left lobe & $40(42.6)$ & $59(43.1)$ \\
\hline Lung & $108(67.1)$ & $182(54.3)$ \\
\hline Right upper lobe & $15(11.1)$ & $21(11.5)$ \\
\hline Right lower lobe & $52(38.2)$ & $66(36.3)$ \\
\hline Right intermediate lobe & $11(8.1)$ & $16(8.8)$ \\
\hline Left upper lobe & $19(13.9)$ & $26(14.3)$ \\
\hline Left lower lobe & $39(28.7)$ & $53(29.1)$ \\
\hline Other sites & $15(9.3)$ & $16(4.8)$ \\
\hline Spleen & $4(2.5)$ & $5(31.25)$ \\
\hline Kidney & $4(2.5)$ & $4(25)$ \\
\hline Brain & $3(1.9)$ & $3(18.75)$ \\
\hline Colon & $2(1.2)$ & $2(12.5)$ \\
\hline Heart & $1(0.6)$ & $1(6.25)$ \\
\hline Eye & $1(0.6)$ & $1(6.25)$ \\
\hline Total & $161(100)$ & $335(100)$ \\
\hline The & & \\
\hline
\end{tabular}

$\mathrm{a}$ The values are presented as No. (\%). 
Fahimzad A et al.

\begin{tabular}{lc}
\hline \multicolumn{2}{l}{ Table 3. Chief Complaints of the 161 Patients ${ }^{\mathrm{a}}$} \\
\hline Chief Complaint & Values \\
\hline Fever & $57(35.4)$ \\
\hline Abdominal pain & $51(31.7)$ \\
\hline Cough & $48(29.8)$ \\
Chest pain & $34(21.1)$ \\
\hline Dyspnea & $34(21.1)$ \\
\hline Nausea/vomiting & $21(13)$ \\
Weight loss & $20(12.4)$ \\
\hline Anorexia & $20(12.4)$ \\
\hline Abdominal mass & $15(9.3)$ \\
\hline Pulmonary effusion & $14(8.7)$ \\
\hline Hepatomegaly & $12(7.5)$ \\
\hline Hemoptysis & $11(6.8)$ \\
\hline Lung abscess & $11(6.8)$ \\
\hline Respiratory distress & $8(5)$ \\
\hline Allergic reaction & $6(3.7)$ \\
\hline Cholestasis & $3(1.9)$ \\
\hline Urinary tract infection & $3(1.9)$ \\
\hline Biliary colic & $2(1.2)$ \\
\hline Liver abscess & $2(1.2)$ \\
\hline Splenomegaly & $2(1.2)$ \\
\hline Seizure & $2(1.2)$ \\
\hline Incidental findings & $24(14.9)$ \\
\hline a The values are presented as No. (\%). & \\
\hline
\end{tabular}

\begin{tabular}{|lc}
\hline \multicolumn{2}{l}{ Table 4. Radiological Findings of the 161 Patients } \\
\hline \multicolumn{1}{l}{ Radiologic Findings } & \multicolumn{1}{l}{ Values } \\
\hline Chest X-ray, $\mathbf{n}=\mathbf{7 9}$ & \\
\hline Normal & $9(11.4)$ \\
\hline Abnormal & $70(88.6)$ \\
\hline Pure cyst & $35(44.3)$ \\
\hline Ruptured & $21(26.6)$ \\
\hline Mass & $7(8.9)$ \\
\hline Abscess formation & $5(6.3)$ \\
\hline Calcification & $2(2.5)$ \\
\hline Sonography, $=\mathbf{8 7}$ & \\
\hline Normal & $4(4)$ \\
\hline Abnormal & $83(96)$ \\
\hline Pure cyst & $55(52.4)$ \\
\hline Daughter cyst & $14(13.3)$ \\
\hline Ruptured & $7(6.7)$ \\
\hline Calcification & $3(2.9)$ \\
\hline Coarse echo & $2(1.9)$ \\
\hline Mass & $1(1)$ \\
\hline Abscess formation & $1(1)$ \\
\hline Computed tomography scan, $\mathbf{n}=\mathbf{8 7}$ & \\
\hline Normal & $0(0)$ \\
\hline Abnormal & $87(100)$ \\
\hline Pure cyst & $45(51.7)$ \\
\hline Ruptured & $18(20.7)$ \\
\hline Abscess formation & $9(10.3)$ \\
\hline Daughter cyst & $7(8)$ \\
\hline Mass & $5(5.7)$ \\
\hline Calcification & $3(3.4)$ \\
\hline The values are presented as No. (\%). \\
\hline
\end{tabular}

Overall, 143 (89\%) patients underwent surgery, 12 (7\%) patients were treated with percutaneous aspiration-injection-reaspiration drainage, and 6 (4\%) patients were prescribed medication. Four out of these 6 patients were transferred to other hospitals for surgery.

\section{Discussion}

HD is still a health hazard in endemic countries (14). In the present study on 161 children in an age range of 1 - 15 years old, the demographical characteristics and infected sites, clinical presentations, paraclinical data, and treatment strategy were assessed. The majority of the study population were male (61.5\% vs. $49.1 \%$ ), and the mean age was $9.25 \pm 3.37$ years. Based on our findings, the lung was the most commonly involved organ (67\%), followed by the liver (44\%), and the combined organ involvement was seen in $19.8 \%$ of the cases. Generally, the right side was the dominant site of infection (54\%). Laboratory data showed elevated eosinophil counts in $41 \%$ and ESR/CRP in $18.6 \%$ of the patients. Chest X-ray and abdominal sonography constituted the principal imaging modalities with respective accuracy rates of $88 \%$ and $96 \%$.

The mean age of our patients was $9.25 \pm 3.37$ years, and $49.1 \%$ of them were in the age range between 6 and 10 years old. Males and females comprised $61.5 \%$ and $38.5 \%$ of the study population, correspondingly (male-to-female ratio $=1.6: 1$ ). Vlad et al. ( 8 ) studied 82 cases at a mean age of 10.8 years, the majority of them being between 10 and 14 years old. The female-to-male ratio was 1.6:1 (8). Djuricic et al. (18) reported the mean age of $10.1 \pm 3.8$ years in their study, which included 149 patients under 18 years of age. The authors found no significant difference in terms of the gender of their patients. In a large Iranian study, Mirshemirani et al. (1) reported the mean age of $11.8 \pm 4.6$ years in 100 patients. In our study, chiming in with the other studies, pre-adolescent years (between 8 and 12 years old) accounted for the most frequent age at clinical presentation. In Iran, various studies have demonstrated that boys are more likely to be infected by Eosinophilic gastroenteritis than girls. It should also be borne in mind that in Iran, boys tend to spend more time outdoors than girls, which can explain the higher incidence of HD in the male cases in our study.

Chaouachi et al.(17) studied 1195 cases of the hydatid cyst in children aged between 2 and 15 years at the Children's Hospital in Tunis and reported that the most commonly involved organ was the lung (in 643 cases), followed by the liver (in 486 cases). Their result is similar to that in our study insofar as the lung was the most commonly involved organ (49.7\%) in our patients, which is concordant with the results of some other similar studies on children $(3,4,11)$. Nevertheless, there are some other studies that show a larger number of hydatid cysts in the liver than in the lung among children $(8,18,19)$. Various genotypes of Echinococcus granulosus isolated form different animal sources can be responsible for the heterogeneity of the results and may contribute to a clinically or histologi- 
cally heterogeneous disease $(20,21)$. Combined liver and lung involvement was detected in $15.5 \%$ of our cases, with the percentage of other combinations of the infected sites being $4.7 \%$, which is in line with some other surveys performed in children $(6 \%-16 \%)(18,22,23)$. It is vitally important that the combined organ involvement not be missed because the maltreatment of the hydatid cyst can result in recurrence in patients.

The frequency of the uncommon anatomical locations of the hydatid cysts in the present study was 9.3\%; the spleen and kidney comprised the majority of such locations. These results are slightly higher than those in the literature on the prevalence of hydatid cysts in the spleen (0.9\% - 8\%) and kidney $(18,23-33)$.

Single organ involvement was $80.2 \%$ in our study, and the single-to-multiple-organ ratio was 4:1, which is similar to those reported by Oudni-M'Rad et al. (4.3:1 in children) (23) and Talaiezadeh and Maraghi (5.7:1 in children) (34). The highest ratio was reported by Al-Shibani et al. (38:1) in cases under 20 years old (35).

Only a few studies have reported such laboratory data as eosinophil or WBC counts and ESR values (36-38). In a review article by Moro and Schantz (39), eosinophilia was found in fewer than $25 \%$ of the cases with HD. Our results showed eosinophilia ( $\geq 500 / \mathrm{micL})$ in $41 \%$ and ESR $\geq 30$ or positive CRP in $18.6 \%$ of the study population. We used a value range that was different from the one employed by Vlad et al. (8) as they found higher figures in their survey (eosinophilia $\geq$ $5 \%$ in $59 \%$ and ESR $\geq 10$ in $68.7 \%$ of the pediatric patients). We think that the higher rate of this laboratory marker can be related to the higher risk of complications such as rupture and, accordingly, recommend that sufficient attention be paid to these results in hydatidosis patients.

Among our pediatric patients, the lung was the most commonly involved organ. We would, therefore, urge that physicians be aware of different radiological forms of echinococcosis on chest X-ray in endemic areas and consider the probability of multiple cysts or multiple organ involvement.

\section{Funding/Support}

This study was supported by Pediatrics Infections Research Center (PIRC) of Shahid Beheshti University of Medical Sciences.

\section{References}

1. Mirshemirani A, Khaleghnejad A, Kouranloo J, Sadeghian N, Rouzrokh M, Hasas-Yeganeh S. Liver Hydatid Cyst in Children (A 14-year Review). Iran J Pediatr. 2011;21(3):385-9.

2. Harandi MF, Hobbs RP, Adams PJ, Mobedi I, Morgan-Ryan UM, Thompson RC. Molecular and morphological characterization of Echinococcus granulosus of human and animal origin in Iran Parasitology. 2002;125(Pt 4):367-73.

3. Tensaw IM. Hydatid cyst in children. Ann Ped Surg. 2010;6(2):98-104

4. Cherry J, Demmler-Harrison GJ, Kaplan SL, Steinbach WJ, Hotez PJ. Feigin and Cherry's Textbook of Pediatric Infectious Diseases.: Elsevier - Health Sciences Division; 2013.

5. Mandell GL, Bennett JE, Dolin R. Principles and Practice of Infectious Diseases.: Elsevier Books, Oxford; 2004.
6. Sadjjadi SM. Present situation of echinococcosis in the Middle East and Arabic North Africa. Parasitol Int. 2006;55 Suppl:S197-202.

7. Rokni MB. The present status of human helminthic diseases in Iran. Ann Trop Med Parasitol. 2008;102(4):283-95.

8. Vlad DC, Neghina AM, Dumitrascu V, Marincu I, Neghina R, Calma CL. Cystic echinococcosis in children and adults: a sevenyear comparative study in western Romania. Foodborne Pathog Dis. 2013;10(2):189-95.

9. Schantz PM, Kern P, Brunetti E. Echinococcosis. Tropical Infectious Diseases: Principles, Pathogens \& Practice.; 2011. pp. 824-38.

10. Celik M, Senol C, Keles M, Halezeroglu S, Urek S, Haciibrahimoglu $\mathrm{G}$, et al. Surgical treatment of pulmonary hydatid disease in children: report of 122 cases.J Pediatr Surg. 2000;35(12):1710-3.

11. Beggs I. The radiology of hydatid disease. AJR Am J Roentgenol. 1985;145(3):639-48.

12. Karaoglanoglu N. Giant hydatid lung cysts. European Journal of Cardio-Thoracic Surgery. 2001;19(6):914-7.

13. Khan RA, Wahab S, Chana RS, Fareed R. Isolated retroperitoneal hydatid cyst in a child: a rare cause of acute scrotal swelling? J Pediatr Surg. 2010;45(8):1717-9.

14. Mirshemirani A, Razavi S, Sadeghian N. Surgical treatment of pulmonary hydatid cyst in 72 children. Tanaffos. 2009;8(1):56-61.

15. Muller R, Wakelin D. Worms and Human Disease. 2002.

16. Brunetti E, White ACJ. Cestode infestations: hydatid disease and cysticercosis. Infect Dis Clin North Am. 2012;26(2):421-35.

17. Chaouachi B, Ben Salah S, Lakhoua R, Hammou A, Gharbi HA, Saied $\mathrm{H}$. [Hydatid cysts in children. Diagnostic and therapeutic aspects. Apropos of 1195 cases]. Ann Pediatr (Paris). 1989;36(7):441-4.

18. Djuricic SM, Grebeldinger S, Kafka DI, Djan I, Vukadin M Vasiljevic ZV. Cystic echinococcosis in children - the seventeenyear experience of two large medical centers in Serbia. Parasitol Int. 2010;59(2):257-61.

19. Şehito ulları A. Our results in surgical treatment of hydatid cyst of the lungs. Eur J General Med. 2007;4(1):5-8.

20. Vahedi MA, Vahedi ML. Demographics of patients with surgical and nonsurgical cystic echinococcosis in East Azerbaijan from 2001 to 2012. PakJ Biol Sci. 2012;15(4):186-91.

21. Ahmadi N, Dalimi A. Characterization of Echinococcus granulosus isolates from human, sheep and camel in Iran. Infect Genet Evol. 2006;6(2):85-90.

22. Talaiezadeh A, Paziar F. The factors of arteriovenous fistula failure in hemodialysis patient. Saudi Med J. 2006;27(1):114-6.

23. Oudni-M'Rad M, M'Rad S, Gorcii M, Mekki M, Belguith M, Harrabi I, et al. [Cystic echinococcosis in children in Tunisia: fertility and case distribution of hydatid cysts]. Bull Soc Pathol Exot. 2007;100(1):10-3.

24. Col C, Col M, Lafci H. Unusual localizations of hydatid disease. Acta Med Austriaca. 2003;30(2):61-4.

25. Dopchiz MC, Elissondo MC, Andresiuk MV, Maiorini E, Gutierrez AM, Muzulin PM, et al. Pediatric hydatidosis in the south-east of the Buenos Aires province, Argentina. Rev Argent Microbiol. 2009;41(2):105-11.

26. Moreno J, Tellez CJ, Pardo FJ. [Hydatid disease in the Department of Health \#2 of the Valencian Community (Spain)]. Rev Esp Quimioter. 2009;22(2):62-7.

27. Hamamci EO, Besim H, Korkmaz A. Unusual locations of hydatid disease and surgical approach. ANZ J Surg. 2004;74(5):356-60.

28. Prousalidis J, Tzardinoglou K, Sgouradis L, Katsohis C, Aletras H. Uncommon sites of hydatid disease. World J Surg. 1998;22(1):17-22.

29. Tsaroucha AK, Polychronidis AC, Lyrantzopoulos N, Pitiakoudis MS, Karayiannakis AJ, Manolas KJ, et al. Hydatid disease of the abdomen and other locations. World J Surg. 2005;29(9):1161-5.

30. Zahawi HM, Hameed OK, Abalkhail AA. The possible role of the age of the human host in determining the localization of hydatid cysts. Ann Trop Med Parasitol. 1999;93(6):621-7.

31. Ernest E, Nonga HE, Kynsieri N, Cleaveland S. A retrospective survey of human hydatidosis based on hospital records during the period 1990-2003 in Ngorongoro, Tanzania. Zoonoses Public Health. 2010;57(7-8):e124-9.

32. Sarkari B, Sadjjadi SM, Beheshtian MM, Aghaee M, Sedaghat F. Human cystic echinococcosis in Yasuj District in Southwest of Iran: 


\section{Fahimzad A et al.}

an epidemiological study of seroprevalence and surgical cases over a ten-year period. Zoonoses Public Health. 2010;57(2):146-50.

33. Rostami Nejad N, Hoseinkhan N, Nazemalhosseini E, Cheraghipour K, Abdinia E, Zali MR. An analysis of hydatid cyst surgeries in patients referred to hospitals in Khorram-Abad, Lorestan during 2002-06. Iranian J Parasitol. 2007;2:29-33.

34. Talaiezadeh AH, Maraghi S. Hydatid disease in children: A different pattern than adults. Pakistan J Med Sci. 2006;22(3):329-32.

35. Al-Shibani LA, Al-Eryani SM, Azazy AA, Al-Mekhlafi AM. Cases of hydatidosis in patients referred to Governmental hospitals for cyst removal in Sana'a City, Republic of Yemen. Trop Biomed. 2012;29(1):18-23.
36. Safioleas M, Misiakos EP, Dosios T, Manti C, Lambrou P, Skalkeas G. Surgical treatment for lung hydatid disease. World J Surg. 1999;23(11):1181-5.

37. Ahmadi NA, Hamidi M. A retrospective analysis of human cystic echinococcosis in Hamedan province, an endemic region of Iran. Ann Trop Med Parasitol. 2008;102(7):603-9.

38. Gonlugur U, Ozcelik S, Gonlugur TE, Arici S, Celiksoz A, Elagoz $S$, et al. The retrospective annual surgical incidence of cystic echinococcosis in Sivas, Turkey. Zoonoses Public Health. 2009;56(5):209-14.

39. Moro P, Schantz PM. Echinococcosis: a review. Int J Infect Dis. 2009;13(2):125-33. 